tially more frequent in men in the Pima population. We also observed this in the Pima diabetic sample in the WHO Multinational Study. The Pima male diabetics in that study had an average prevalence of $\mathrm{Q}$ wave abnormalities almost exactly the average of the men in the whole study (14 populations), whereas the Pima women diabetics were near the low end of the distribution. These data are more recent than those reported by Ingelfinger et al. and has the added advantage that all ECGs for the international comparisons were coded by the same pair of observers. Thus, it is arguable that the Pima are in a transitional state, the men, if not the women, moving towards a higher incidence of coronary heart disease. Incidentally, $Q$ wave abnormality rates in the Oklahoma Indian diabetics in the WHO study were, in both sexes, amongst the highest observed. The dietary data which Dr. Reaven quotes are based upon women only and were restricted to the age group $25-44$ years. It is certainly true that the fat intake was similar to the US average and that total cholesterol levels were, on average, relatively low. However, these women have a phenomenally high frequency of gall bladder disease and the role of vagaries of cholesterol metabolism in this population has been only partly explored.

The one thing that all diabetics get is advice or recommendations concerning diet. Those involved in treating patients cannot sit back and wait for those further studies which Dr. Reaven wants. They have to have a policy for 1981. Total calorie intake can only be determined by experience with the individual diabetic. The distribution of these calories is a policy matter and I agree with that outlined in the letter of Dr. Mann and his colleagues (Diabetologia 20:507-508),-i.e. 'for the majority of diabetics the diet could safely contain $55 \%$ of carbohydrate calories provided that it was high in dietary fibre and low in simple sugar'. I would add that most of the general population would be better off on such a diet.

Yours sincerely,

R. J. Jarrett

\section{References}

1. Ingelfinger JA, Bennett PH, Liebow IM, Miller M(1976) Coronary heart disease in the Pima Indians; Electrocardiographic findings and postmortem evidence of myocardial infarction in a population with a high prevalence of diabetes mellitus. Diabetes 25:561-565

2. Reid JM, Fullmer SD, Pettigrew KD, Burch TA, Bennett PH, Miller M, Whedon GD (1971) Nutrient intake of Pima Indian women: relationships to diabetes mellitus and gallbladder disease. Am J Clin Nutr 24: 1281-1289

\section{R. J. Jarrett}

Department of Community Medicine

Guy's Hospital Medical School

London Bridge

London SE1 9 RT, UK

\title{
Renal Collagen Glucosyltransferase Activity Following Islet Transplantation in Streptozotocin-Diabetic Rats
}

\begin{abstract}
Sir,
In a recent article in Diabetologia, Chang et al. [1] reported increased renal galactosyl-hydroxylysine-glucosyltransferase (EC 2.4.1.66) activity in diabetic Chinese hamsters, using a modification of the assay system recently described by Draeger and Weithmann [2]. Spiro and Spiro [3] were the first to report elevated renal activity of this collagen basement membrane enzyme in alloxan-diabetic rats, suggesting that this reflected increased basement membrane synthesis in diabetes mellitus; with insulin therapy, the enzyme activity returned to normal in some cases. Other workers, however, could not confirm these findings [4] and studies in streptozotocindiabetic rats have given controversial results [5-7].

We have therefore determined the glucosyltransferase activity using the recently described assay system [2] in 12 age-matched normal rats, seven diabetic and seven islet-transplanted diabetic rats of the same inbred strain (Lewis/Han). For this study a moderate diabetes (mean fasting blood glucose value about $14 \mathrm{mmol} / \mathrm{l}$ ) was induced at the age of 4 months by IV injection of streptozotocin $65 \mathrm{mg} / \mathrm{kg}$. Six weeks after induction of diabetes islet transplantation was performed in seven rats as previously described [8]. The remaining seven diabetic rats and 12 normal rats served as controls. All animals were killed following pentobarbital anaesthesia at age 12-15 months. Part of one kidney was used for histological exami-
\end{abstract}

nation as described earlier [8]. The remaining tissue and the contralateral kidney were used for enzyme studies. Statistical analysis was performed using Student's t-test.

Six islet-transplanted rats showed normal weight gain, blood glucose and insulin levels throughout the investigation period (legend Fig. 1). In one rat, however, diabetes recurred for unknown reasons 8 months after islet transplantation. The histological investigations on kidneys from diabetic rats revealed a marked segmental or global enlargement of the glomerular mesangium, thickening of capillary walls, narrowing of the capillary lumina, typical exudative lesions ('caps', 'drop lesions'), and in some cases glomerulocapsular adhesions. On the other hand, islet-transplanted animals demonstrated only age-related glomerular changes. Using light microscopy their glomeruli did not differ from those examined in age-matched normal controls. As reported at the EASD Meeting in 1980 [9], diabetic controls had elevated glucosyltransferase activities compared with normal controls (Fig. 1). Although our data showed relatively wide scatter and overlap between groups, the effect of diabetes was significant $(p<0.02)$. In contrast, islet-transplanted rats had low enzyme levels. Their group mean value dif * fered significantly from that in diabetic controls.

Our results confirm recent findings that streptozotocin-induced diabetes mellitus in rats is followed by an elevated kidney collagen 


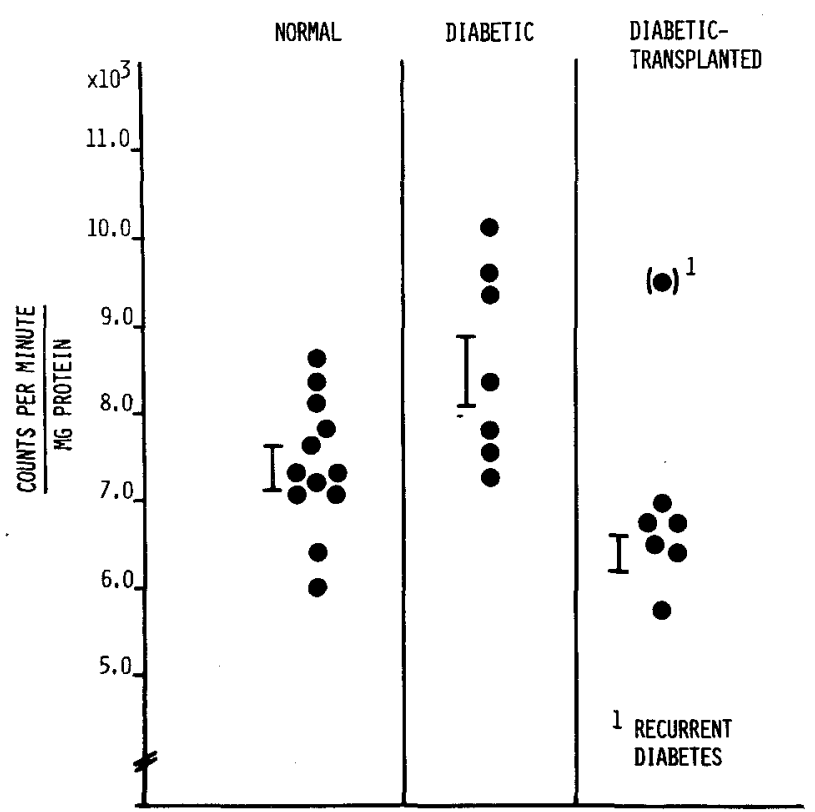

Fig. 1. Renal collagen glucosyltransferase activity in 12 age-matched normal rats, seven diabetic and seven islet-transplanted diabetic rats. Individual values and mean values $\pm S E M$ are given. The mean value in the diabetic controls differed significantly from that in normal $(p<0.02)$ and islet-transplanted rats $(p<0.005)$. On day of kidney examination islet-transplanted rats showed nearly normal body weight $(338.3 \pm 9.2$ versus $399.2 \pm 13.5 \mathrm{~g})$, normal blood glucose $(5.4 \pm 1.0$ versus $4.1 \pm 0.3 \mathrm{mmol} / \mathrm{l})$ and insulin levels $(42.8$ \pm 7.2 versus $38.2 \pm 1.8 \mathrm{mU} / 1$ ). Diabetic controls showed low body weight $(206.4 \pm 15.6 \mathrm{~g})$, hyperglycaemia $(13.8 \pm 1.6 \mathrm{mmol} / \mathrm{l})$ and hypoinsulinaemia $(21.3 \pm 1.3 \mathrm{mU} / \mathrm{l})$

glucosyltransferase activity [5, 6]. Furthermore, it could be demonstrated that high enzyme levels coincide with typical diabetic glomerular kidney lesions. In addition, the data show that early islet transplantation restores blood glucose homeostasis followed by normal enzyme activity. This may contribute to the prevention of morphological kidney changes in islet-transplanted rats. In contrast, we have shown that the high insulin doses, necessary for good metabolic control, produce raised enzyme activity using the same assay system (unpublished observations). Thus, our results indicate a possible additional therapeutic effect of islet transplantation, at least in experimental diabetes mellitus.

Yours sincerely,

R. G. Bretzel, A. Menden, M. Richardt, D. G. Brocks, K. E. Draeger and K. Federlin

\section{References}

1. Chang AY, Noble RE, Perry CS, Greenberg HS (1980) Renal glucosyltransferase activity in highly-inbred spontaneously diabetic Chinese hamsters. Diabetologia 19:40-44

2. Draeger KE, Weithmann KU (1978) A modified assay system for collagen glucosyltransferase. Diabetologia 15: 125-128

3. Spiro RG, Spiro MJ (1971) Effect of diabetes on the biosynthesis of the renal glomerular basement membrane. Studies on the glucosyltransferase. Diabetes 20:641-648

4. Duhault J, Lonchampt M (1977) Glucosyltransferase activity and diabetic microangiopathy. Biomedicine 27: 127-131

5. Grant ME, Harwood R, Williams IF (1976) Increased synthesis of glomerular basement membrane collagen in streptozotocin diabetes. J Physiol 257: 56-57

6. Haft DE, Reddi AS (1979) Glucosyltransferase activity in kidney fractions of normal and streptozotocin-diabetic rats. Biochim $\mathrm{Bi}$ ophys Acta 584: 1-10

7. Risteli J, Koivisto VA, Akerblom HK, Kivirikko KI (1976) Intracellular enzymes of collagen biosynthesis in rat kidney in streptozotocin diabetes. Diabetes 25: 1066-1070

8. Bretzel RG, Manns E, Breidenbach CH, Hofmann I, Federlin K (1979) Long-term studies with syngeneic islet transplantation in experimental diabetes mellitus. Diabetologia 14:222

9. Bretzel RG, Schneider J, Draeger KE, Weise M, Federlin K (1980) Reversibility of diabetic glomerular and tubular changes by islet transplantation. Diabetologia 19:260-261

R. G. Bretzel, M. D.

Department of Internal Medicine

Justus-Liebig-University

Rodthohl 6

D-6300 Giessen

Federal Republic of Germany 